Alfredo Morabia, Michael C. Costanza

Division of Clinical Epidemiology, Canton Hospital, University of Geneva

On behalf of the WHO Collaborative Study of Neoplasia and Steroid Contraceptives*

* See Appendix for details of data collection centers and principal participants.

\title{
Reproductive factors and incidence of breast cancer: An international ecological study
}

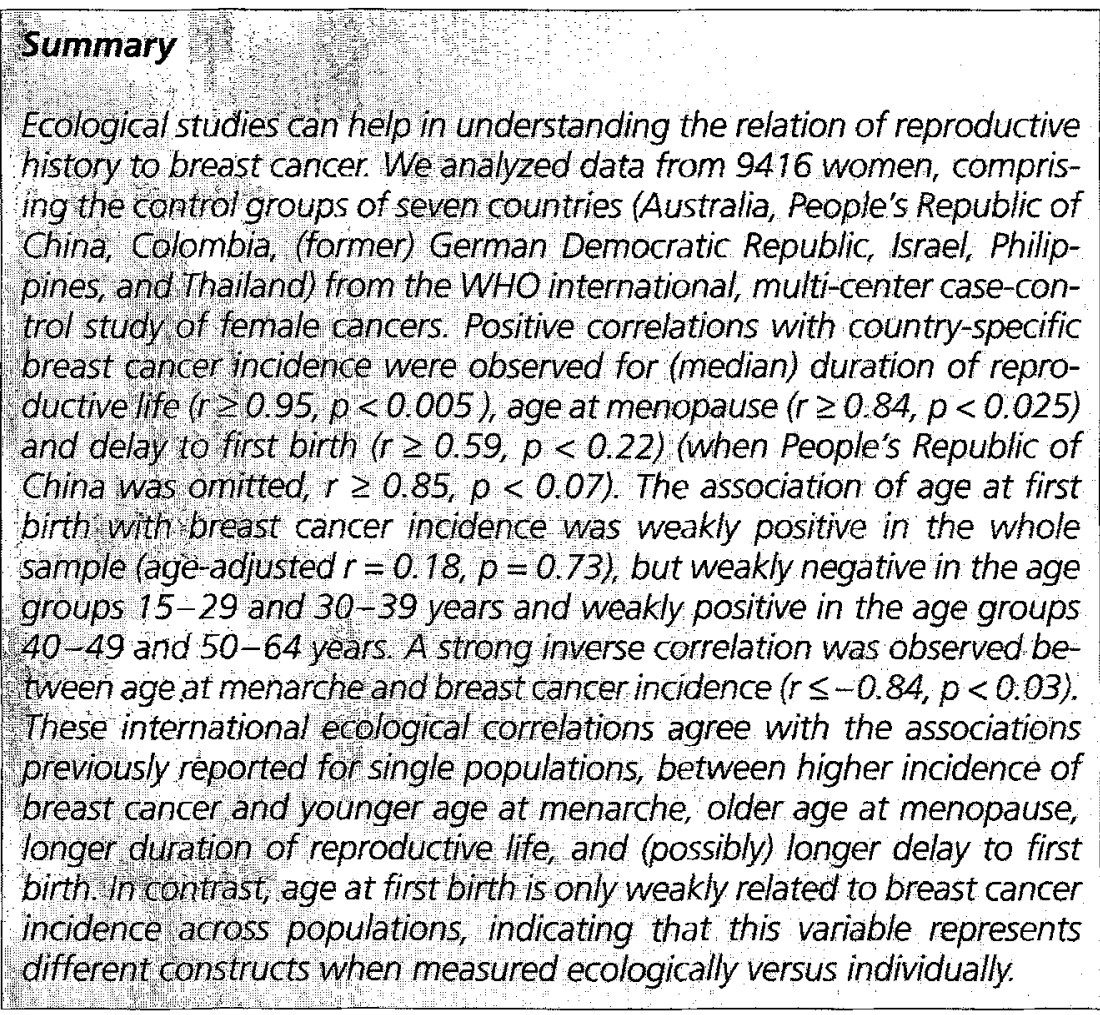

It has been found with relative consistency in Western ${ }^{1}$ as well as nonWestern populations ${ }^{2}$ that a younger age at menarche, older age at first birth, and older age at menopause conferred a higher risk of breast cancer. Biological bases of these associations, including the effects of estrogens and gestagens on cell proliferation, have now been thoroughly investigated ${ }^{3}$.

There is, however, important variability in these associations across populations. An international study showed that younger age at menarche was associated with increased risk of breast cancer in Japan and Taïwan, countries with a late mean age at menarche (14.6 years in cases and 14.8 years in controls), but was not related to breast cancer risk in Brazil, Greece, Yugoslavia, Wales and the U.S., where the mean ages at menarche were about one year younger than in Japan and Taiwan ${ }^{4}$. Similarly, the strength of the association between age at first birth and breast cancer risk has varied considerably across studies $^{5}$. Weaker associations have been observed in populations where a first birth before age 20 is relatively uncommon. In the collaborative study conducted in Greece, U.S., U.K., Japan, Taiwan, Brazil, and Slovenia, a first pregnancy before the age of 18 was associated with a two-thirds reduction in risk compared to a first pregnancy over the age of $35^{6}$. In contrast, in a meta-analysis of eight studies from the Nordic European countries, women with a first birth before the age of 20 years had only a $40 \%$ decrease in risk compared to those with a first birth after the age of 35 years ${ }^{1}$. These international studies are not necessarily consistent with all epidemiologic studies conducted in the particular countries, but the point here is that the relative homogeneity of reproductive histories within specific populations may negatively affect statistical power and explain at least in 
part the inconsistent findings across individual-level studies.

One way to address the lack of variability of exposure and of risk usually found in single populations is to compare different populations across the world and to correlate average population characteristics with incidence or mortality of a given disease ${ }^{7,8}$. For example, in the collaborative study conducted in Greece, U.S., U.K., Japan, Taiwan, Brazil, and Slovenia, age at first birth ranged from 15 to 40 years ${ }^{6}$, which is unusual for most Western countries $^{9,10}$. International ecological study designs cannot resolve problems related to lack of variability of exposure or of risk - indeed, only comparisons of individuallevel data across different populations could ultimately serve that purpose. However, international ecologic studies can serve to augment insights into associations observed in individual level studies $^{11}$ of the relationship between breast cancer and reproductive history.

In this study we present the correlations between the incidence of breast cancer reported by tumor registries in seven different locations of the world and the timing of reproductive events based on samples of women from populations belonging to these countries. The diverse study populations serve to indicate the whole range of observable variability in the world population.

\section{Subjects and methods}

\section{Study women}

The study sample consisted of 9416 of the 18997 women comprising the control group in a World Health Organization (WHO) international multi-center case-control study of female cancers, descriptions of which and primary results therefrom have been previously reported based on data collected from 1979 to 1986 by the WHO Collaborative Study of Neoplasia and Steroid Contraceptives ${ }^{12-15}$. Analyses for the present report were based on a subset of the data from those control women plus further data collected on additional control women for the WHO study as subject recruitment continued through 1988. Of the 13 populations in 11 different countries that were part of the original WHO study, we included in the present report only the seven populations which had corresponding tumor registry data on breast cancer incidence available in existing published sources (Australia, People's Republic of China, Colombia, (former) German Democratic Republic, Israel, Philippines, and one region in Thailand). The latest incidence data available for Nigeria were too old (1960-1969).

The WHO study control group consisted of women who had been admitted to other than obstetricsgynecology hospital wards and who were free of medical conditions possibly thought to alter contraceptive practices (i.e., cardiovascular and circulatory diseases, diabetes, chronic renal disease, benign breast disease, cancer, chronic liver disease, and any obstetrical or gynecological condition) (see Table 2 in reference ${ }^{13}$ ). These women were selected from a large variety of different clinics within each sampled region in order to avoid any link between their reproductive characteristics and their likelihood of being recruited into the WHO study. The control women were of the same age and residential origin as the cases. These hospital control patients were interviewed, mostly in the hospital, between 1979 and 1988 using a standardized questionnaire administered by trained female interviewers.

\section{Breast cancer incidence data}

Breast cancer incidence rates (per 100000 women per year) for the seven study populations were abstracted from Volume VI of Cancer Incidence in Five Continents ${ }^{16}$. World age-standardized (i.e., using the world population as reference) rates were employed.

\section{Reproductive variables, statistical} analyses, and sample sizes

The five main study variables (measured in years) used to assess the reproductive histories of the sample women from each study population were age at menarche, delay from menarche to first (live) birth, age at first (live) birth, age at (natural) menopause, and duration of reproductive life (time between menarche and (natural) menopause). For each of the seven study populations we summarized the distributions of the reproductive variables using the median (P50 = $50^{\text {th }}$ percentile) and other percentiles ((P10, P25, P75, P90) for age at menarche; (P10, P25, P75) for delay to and age at first birth; (P10, $\mathrm{P} 25)$ for age at menopause and duration of reproductive life). The ecological relationships between the breast cancer incidence rates and the median (or other percentile) of each reproductive variable across the seven study populations were studied using bivariate scatterplots, least squares regression lines, and Pearson simple and median age-adjusted partial correlation coefficients. To assess potential generation effects the ecologic analyses for each reproductive variable were repeated separately for study women in the four age-atinterview subgroups 15-29, 30-39, $40-49,50-64$ years within each population.

\section{Age at menarche}

Age at menarche was directly reported by the study women during their interview. In the analyses of this (and of all the other) reproductive variables, 20 women who either reported never menstruating 
or whose menstruation status or age at menarche were recorded as unknown were excluded (net total $\mathrm{N}=9396$ ).

Age at menopause and duration of reproductive life

Most of the study women had not yet experienced menopause (either natural or artificial) by the time they were interviewed. Thus, we used Kaplan-Meier survival analysis methodology ${ }^{17}$ to construct the sample distributions of age at menopause and of duration of reproductive life (= age at menopause - age at menarche) for each population, from which the corresponding medians and other percentiles were estimated.

These Kaplan-Meier analyses required information on menopausal status (i.e., censoring) which was not directly reported during the interview. We therefore calculated this information indirectly using a classification algorithm applied to year of last menses, year of interview, year of birth (derived from age), and other relevant reproductive data (see below) that were directly reported during the interview. The logic and results of this classification algorithm are summarized briefly below.

For all menarchal study women, age at menopause was initially calculated as (year of last menses year of birth), regardless of censoring. Study women who were actually classified as having undergone natural menopause (total $\mathrm{N}=1936$ ) were at least required to have had their last reported menses more than one year before their year of interview. Study women who had undergone either a hysterectomy, a double oophorectomy, or any operation/x-ray treatments preventing further menstrual periods at any time before or during their year of interview were classified as having had an artificial menopause (total $\mathrm{N}=642$ ), and their initially calculated age at menopause was consid- ered to be censored at the year of artificial menopause. For premenopausal (including a few pregnant and/or nursing) study women (total $N=6789$ ), their initially calculated age at menopause was considered to be censored at the year of their interview. Study women for whom any of the algorithm calculations involved missing data were classified as missing menopausal status (missing total $\mathrm{N}=49$ ).

The resulting sample sizes for age at menopause (net total $\mathrm{N}=9361$ ) and duration of reproductive life (net total $\mathrm{N}=9360$ ) reflected the exclusions due to missing menopausal status (with $41 \%$ of these due to age at menarche, as noted above), as well as a few additional exclusions due to missing data on age and/or some of the other reproductive variables (e.g., year of last menses, hysterectomy status, etc.) used to calculate menopausal status. The study women from East Germany ((former) German Democratic Republic) were not quite old enough to estimate their median age at menopause. Instead, because the estimated $49.3^{\text {rd }}$ percentile for this population was 51 years, we conservatively estimated the median age at menopause for the German Democratic Republic as 52 years.

Likewise, the study women from Israel were not old enough to estimate their median age at menopause and their median duration of reproductive life. However, the respective sample $38.1^{\text {st }}$ and $44.2^{\text {nd }}$ (the last estimable) percentiles for the latter two variables were 51 and 40 years. Thus, we conservatively estimated the median age at menopause as 52 years and the median duration of reproductive life as 41 years for Israel.

\section{Age at first birth and delay from menarche to first birth}

The vast majority (9411/9416) of the study women provided non- missing interview data on age at first birth. Most (7806/9411), but not all, of these women reported actually having had a live birth. Each of the 1605 nulliparous women had a censored age at first birth (hence also a censored delay from menarche to first birth) taken as: her age at natural menopause if she had experienced a natural menopause; her age at artificial menopause if she had undergone an artificial menopause; and just her age if she was still pre-menopausal. Likewise, the censored delay from menarche to first birth for nulliparous study women was calculated as the difference between their censored age at first birth and their age at menarche.

Kaplan-Meier methodology analogous to that described in the previous section was then employed to estimate the distributions and percentiles of age at first birth and delay from menarche to first birth.

The resulting sample sizes for age at first birth (net total $\mathrm{N}=9385$ ) and delay from menarche to first birth (net total $N=9383$ ) reflected slight reductions for reasons similar to those mentioned in the previous section. The reductions were less extreme here than there because missing values for menopausal status necessarily led to exclusions only for nulliparous women. Multiparous women with valid ages at first birth were not necessarily excluded if they had missing data on menopausal status.

\section{Results}

The breast cancer incidence rates in the seven study countries, together with the specific populations and the years of tumor registry coverage are given in Table 1 . There was a five-fold ratio between the highest $(64.7 / 100000 / \mathrm{yr})$ and the lowest (13.7) breast cancer incidence rates. The highest 


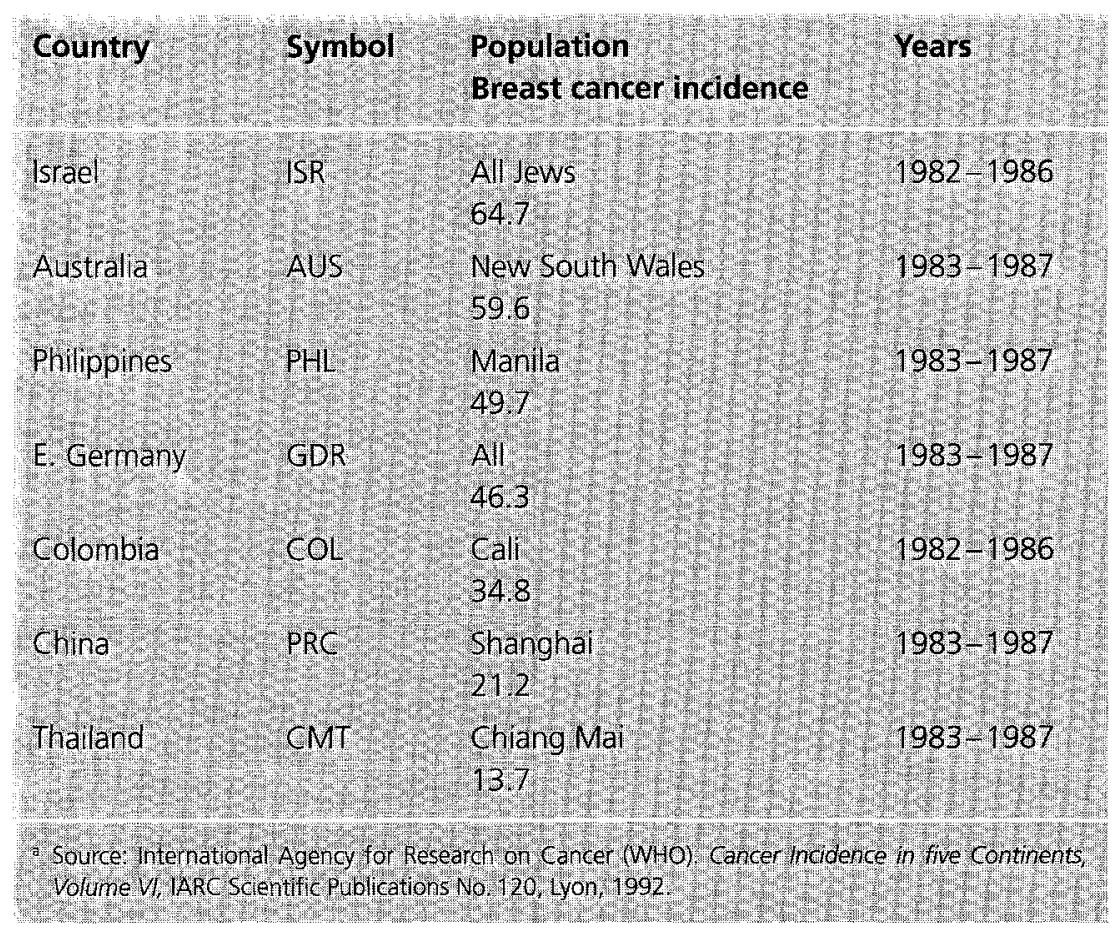

Table 1. World age-standardized breast cancer incidence rates 1 (per 100000 women per year), specific populations and years of registry coverage corresponding to the seven WHO study locations, ordered by decreasing incidence rates.

breast cancer incidence rates were observed in the more Western (Israel and Australia) countries, and the lowest rates in the Asian (Thailand and China) countries.
The interview years, sample sizes, and summaries of the age distributions for each of the WHO study samples are given in Table 2. The study women were relatively young

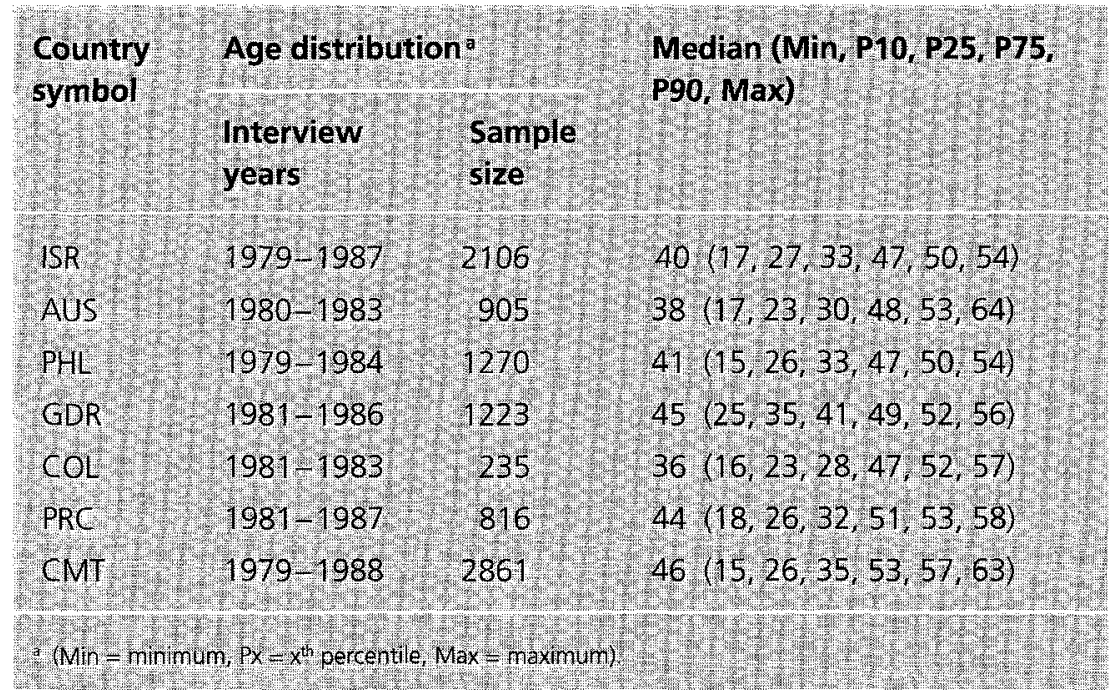

Table 2. Interview years, sample sizes, and age distributions (years) in the seven WHO study samples. (total age range 15-64 years). There was reasonable concordance between the years of tumor registration (1982-1987) and the interview periods of the WHO study (1979-1988), and also between the populations covered by the tumor registries and those that were sampled in the WHO study (see data collection centers in Appendix).

Summaries of the distributions of the five reproductive variables are given in Table 3. Because the study women were so young (see Table 2), the $90^{\text {th }}$ percentiles for age at and delay to first birth could be estimated for only half of the study populations (data not shown). Likewise, the $75^{\text {th }}\left(90^{\text {th }}\right)$ percentiles for age at menopause and duration of reproductive life could be estimated for only two of the study populations (data not shown).

The breast cancer incidence rates (see Table 1) are also presented graphically in the upper left panel of Figure 1. The other scatterplots in Figure 1 depict the relationships between breast cancer incidence and the medians of the five reproductive variables in Table 3. Similar rankings among the countries as seen in Table 1 can be observed on most of the axes for each of the five reproductive variables in Figure 1. For example, Thailand always belongs to the group with older age at menarche, younger age at first birth, and shorter delay to first birth. Thailand has in addition a younger age at menopause and a shorter duration of reproductive life. People's Republic of China behaves as a low-risk country for the two physiologically determined variables (age at menarche and age at menopause) but as a westernized country for the culturally determined variables (age at and delay to first birth).

The Pearson simple and (median) age-adjusted correlations between the breast cancer incidence rates and the medians of each of the five 


\begin{tabular}{|c|c|c|c|c|c|}
\hline $\begin{array}{l}\text { Country } \\
\text { symbol }\end{array}$ & $\begin{array}{l}\text { Age at } \\
\text { menarchea }\end{array}$ & $\begin{array}{l}\text { Delay to } \\
\text { first birth }\end{array}$ & $\begin{array}{l}\text { Age at } \\
\text { first birth }^{b}\end{array}$ & $\begin{array}{l}\text { Age at } \\
\text { menopausec }\end{array}$ & $\begin{array}{l}\text { Duration of } \\
\text { reproductive life }\end{array}$ \\
\hline $\mathrm{SSR}$ & $13(1), 12,14,15)$ & $9(5,7,13)$ & $22(18,20,26)$ & $52^{d}(46,49)$ & $41 \mathrm{e}(32,36)$ \\
\hline Aus & $13(11,12,14,15)$ & $11(5,8,16)$ & $24(18,21,29)$ & $51 \quad(45,48)$ & $38(31,35)$ \\
\hline PHL & $14(12,13,15,16)$ & $10(3,6,16)$ & $23(17,20,30)$ & $50(44,47)$ & $37(30,33)$ \\
\hline $\mathrm{GDR}$ & $14(12,12,15,16)$ & $9(4,6,13)$ & $22(18,20,26)$ & $52^{f}(46,49)$ & $38(32,35)$ \\
\hline $\mathrm{COL}$ & $13(11,12,14,15)$ & $7(3,4,11)$ & $20(16,18,24)$ & $50 \cdot(41,47)$ & $36(28,34)$ \\
\hline $\mathrm{PRC}$ & $15(13,14,16,17)$ & $10(4,7,13)$ & $25(20,23,28)$ & $49(45,47)$ & $34(29,32)$ \\
\hline 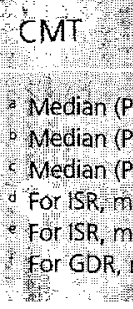 & $\begin{array}{l}16(13,14,17,18) \\
\text { 5, P75, p9o) (Px = x perce } \\
5 \text {, P75) (Kapplan Meier estin } \\
\text { 5) (Kaplan Meier estimates } \\
\text { age at menopause }>51 \text { ye } \\
\text { duration of reproductive lif } \\
\text { lage at menopause } \geq 52 \text { y }\end{array}$ & $6(2,3,10)$ & $22(18,20,26)$ & $49(40,45)$ & $32(24,28)$ \\
\hline
\end{tabular}

Table 3. Medians (percentiles) of reproductive variables (years) in the seven WHO study samples.

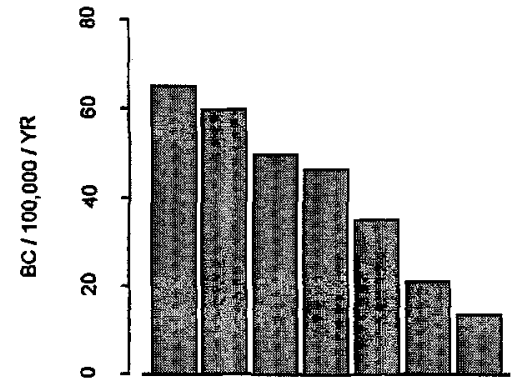

ISR AUS PHL GDR COL PRC CMT
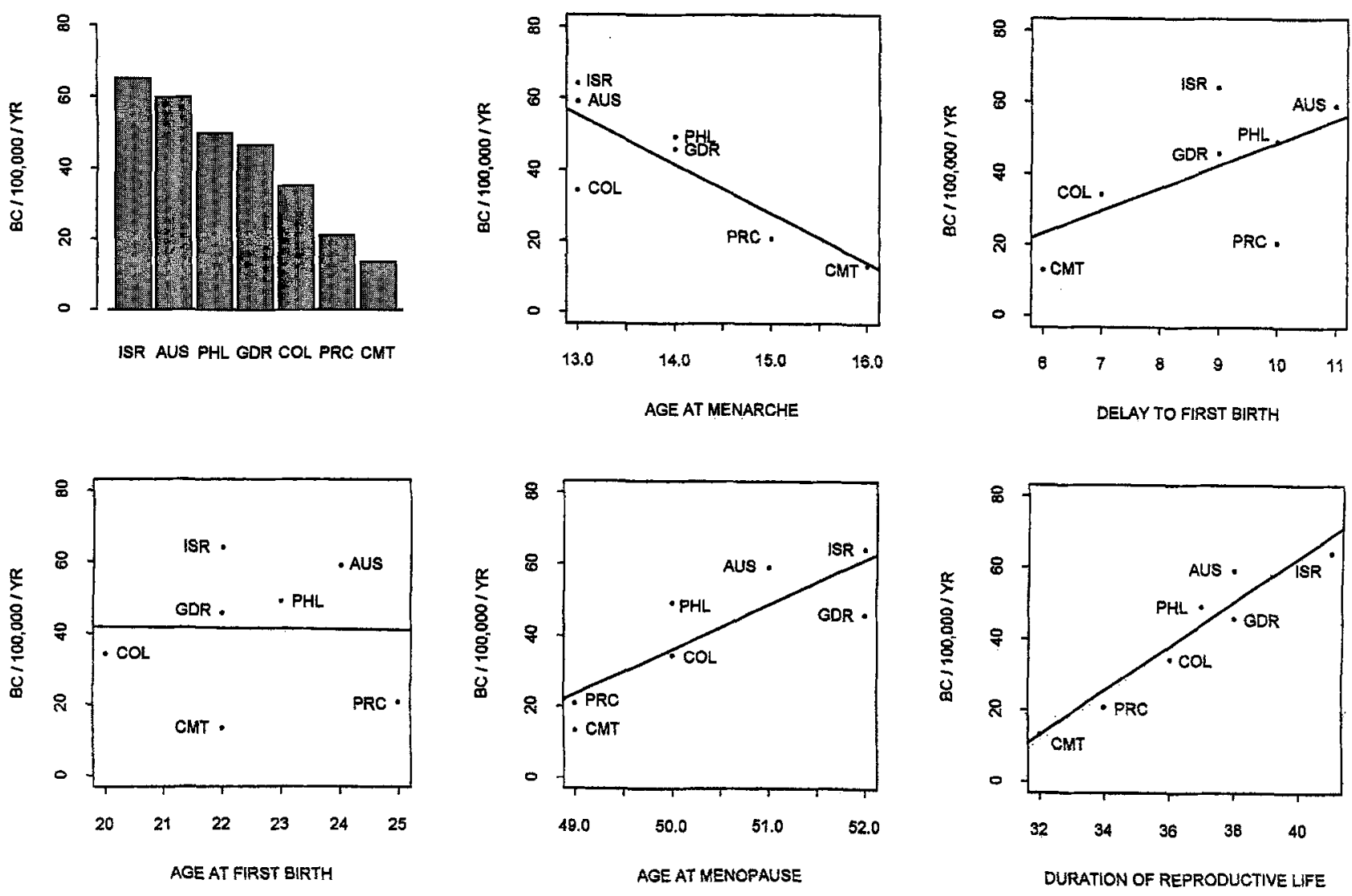

Figure 1. World age-standardized breast cancer incidence per 100000 women per year (BC/100000/yr) (barplot) and relationships between $B C / 100000 / y r$ and medians (50th percentiles) of reproductive variables (scatterplots with least squares regression lines) in seven WHO study locations. 


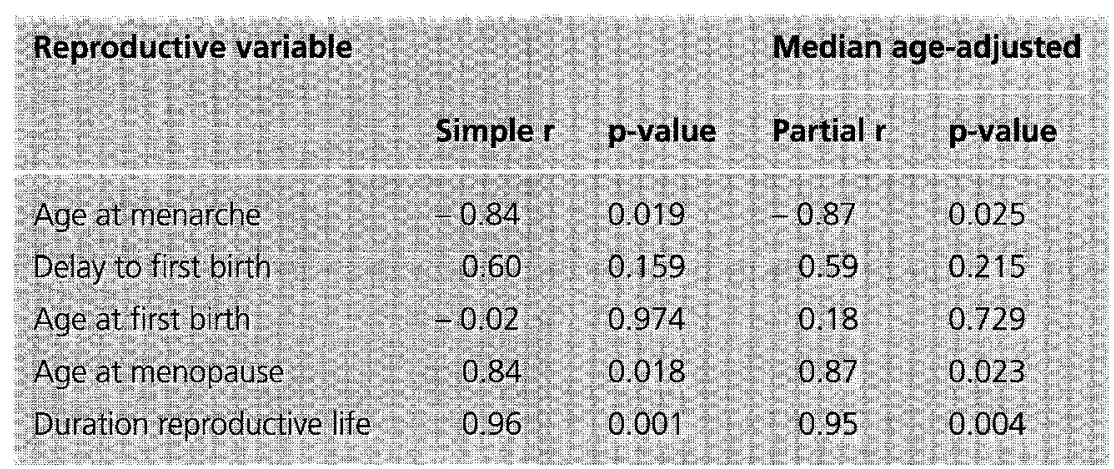

Table 4. Pearson simple correlations (r) and median age-adjusted partial correlations (partial r) between world age-standardized breast cancer incidence rates and the medians (50th percentiles) of reproductive variables for the seven WHO study samples. (Simple r's correspond to the regression lines in Figure 1.)

reproductive variables corresponding to the scatterplots and least squares regression lines in Figure 1 are given in Table 4. Strong positive associations with breast cancer incidence were observed for duration of reproductive life $(\mathrm{r}=0.95$, $\mathrm{p}=0.004$ with age-adjustment) and age at menopause $(r=0.87, p=$ 0.023 with age-adjustment). Conversely, a strong inverse correlation was observed between age at menarche and breast cancer incidence $(r=-0.87, p=0.025$ with age-adjustment). Age at first birth was not associated with breast cancer incidence $(r=0.18, p=0.73$ with age-adjustment). Delay to first birth was moderately positively (but not significantly) associated with breast cancer incidence ( $\mathrm{r}=$ $0.59, \mathrm{p}=0.22$ with age-adjustment). People's Republic of China was an influential point in the latter correlations. When People's Republic of China was omitted, the simple and partial correlations between age at first birth and breast cancer incidence increased to $\mathrm{r}=0.44$ and 0.58 , respectively, but neither was statistically significant (respective $\mathrm{p}=0.38$ and 0.30 ).

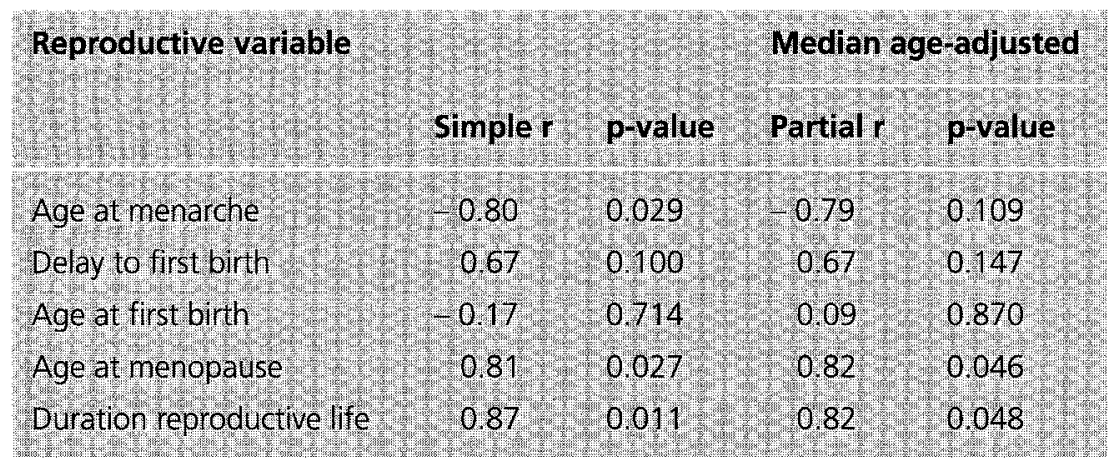

Table 5. Pearson correlations (simple r) and median age-adjusted partial correlations (partial r) between the world age-standardized breast cancer incidence rates and the 25th percentiles of reproductive variables for the seven WHO study samples.
On the other hand, the simple and partial correlations between delay to first birth and breast cancer incidence increased to $\mathrm{r}=0.86$ and 0.85 , respectively, the first of which was statistically significant $(\mathrm{p}=$ 0.029 ) and the second of which was not quite statistically significant $(\mathrm{p}=0.069)$.

Similar qualitative patterns and magnitudes of associations between the breast cancer incidence rates and the $10^{\text {th }}$ and $25^{\text {th }}$ percentiles, and (when estimable) the $75^{\text {th }}$ and $90^{\text {th }}$ percentiles, of the reproductive variables were also observed. The simple and partial correlation results for the $25^{\text {th }}$ percentiles (only), which could be estimated for all countries, are shown in Table 5. As occurred for the medians, omitting People's Republic of China from the calculations led to non-statistically significant increases in the correlations of breast cancer incidence with age at and delay to first birth (data not otherwise shown).

The more culturally determined age at and delay to first birth were the only reproductive variables for which generation effects could be discerned (data not shown except as noted below). Specifically, for most of the populations we found that the study women in the two youngest (15-29 and 30-39 years) age subgroups tended to be older at (correspondingly, to delay slightly longer until) their first birth compared to the study women in the two older (40-49 and 50-64 years) age subgroups $\left(\mathrm{see}^{10}\right)$.

Potential generation effects relative to the overall association between the breast cancer incidence rates and the median ages at first birth (see Figure 1 and Table 4) were assessed by examining the scatterplots with least squares regression lines and the simple correlations between these two variables within each age subgroup shown in Figure 2. The association was weakly positive in each of the 

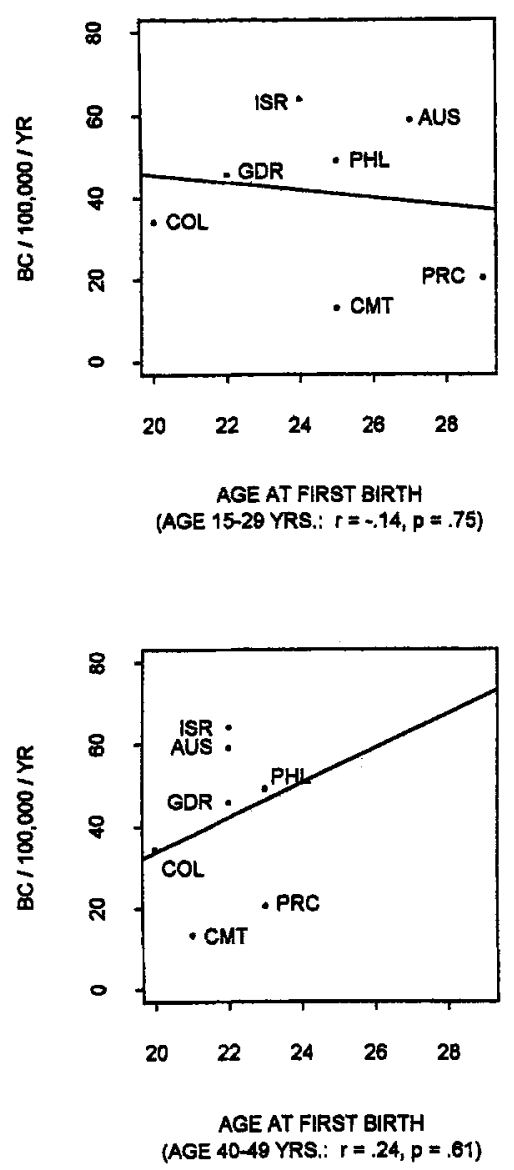
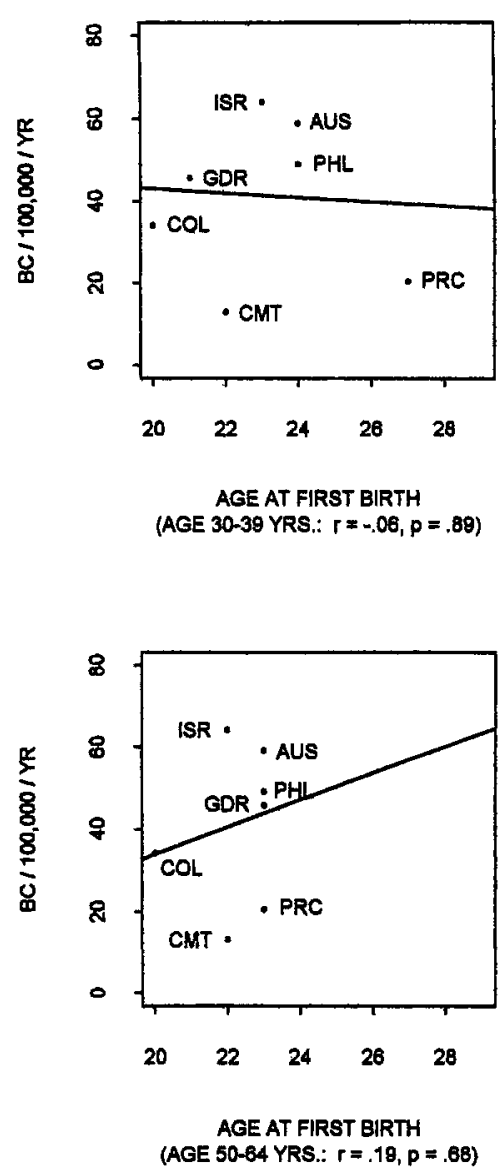

Figure 2. Non-significant (all $p>0.60$ ) correlations between world agestandardized breast cancer incidence per 100000 per year (BC/100000/yr) and median age at first live birth in seven WHO study locations stratified by age subgroups.

age subgroups $40-49$ and $50-64$ years $(r=0.24$ and 0.19 , respectively), but was weakly negative in the age subgroups $15-29$ and $30-39$ years $(r=-0.14$ and -0.06$)$. However, as indicated, none of these correlations were statistically significant (all $\mathrm{p}>0.60$ ). As above, People's Republic of China was an influential point in the latter correlations. When People's Republic of China was omitted, the correlations in the $15-29,30-39,40-49$ and 50-64 years subgroups were all positive $(\mathrm{r}=0.24,0.68,0.59$ and 0.38 , respectively). However again, none reached statistical significance (respective $\mathrm{p}=0.65,0.13$, $0.22,0.46$ ).

\section{Discussion}

This international ecological study shows strong correlations of breast cancer incidence with age at menarche, duration of reproductive life, age at menopause, and (when People's Republic of China is omitted) delay to first birth. For these factors, the ecological study agreed with what has been observed in individual-level studies.

On the other hand, the association of breast cancer incidence with age at first birth (including omission of People's Republic of China and allowance for generation effects) was much weaker than expected from individual-level studies. The correlation was strongly influenced by the atypical behavior of People's Republic of China, which had a low incidence of breast cancer but a late age at first birth. The Chinese policy towards wedding age and parity may have had some influence on the corresponding incidence of breast cancer. The higher age at first birth may explain in part why higher rates of breast cancer were observed in People's Republic of China compared to Thailand. However, such changes in reproductive life may not yet have been followed by full changes in incidence. There is a time lag that is not accounted for in this study.

These results may also indicate that it is not so much the specific age at first birth, but the delay between menarche and first birth that confers the increased breast cancer risk. Russo et al. ${ }^{18}$ have suggested that the susceptibility of the mammary gland to carcinogens may be the highest during the years between menarche and first birth, i.e., when the glandular epithelium has not yet been fully differentiated. If so, the longer the delay to first birth, the higher the risk, irrespective of the specific age at menarche or age at first birth. This interpretation contradicts however other results showing that age at first birth and age at menarche are independent risk factors for breast cancer. For example, Henderson et al. ${ }^{19}$ found that the odds ratio (OR) for breast cancer was 1.58 for menarche $<13$ years, 1.75 for first delivery at $\geq 25$ years, and 2.76 for (menarche $<13 \&$ first delivery at $\geq 25$ ). Thus, the observed OR for the joint effect corresponds to the OR expected under simple multiplicativity $(2.78(1.58 \times 1.75)$.

\section{Limitations and strengths}

We compared reproductive histories obtained from individual women controls participating in an international case-control study with breast cancer incidence data 
derived from country-specific cancer registries that did not cover the exact same target populations. We employed censored data analysis techniques to estimate the percentiles of age at and delay to first birth, age at menopause, and duration of reproductive life because the study women were relatively young. The percentiles estimated from the individual-level data were, of course, aggregated measures, so the study design and the correlations were really fully ecological. Because only seven (six with omission of People's Republic of China) countries were included and because relevant covariate information was unavailable in the source data, we could not effectively adjust the correlations for differences among the countries on the reproductive or other variables (e.g., dietary factors) that are potentially confounded with or related to breast cancer incidence. These are clear limitations of our ecologic study in comparison with traditional individual-level ${ }^{20-23}$ (also with hybrid "aggregate data" multilevel $^{24}$ or other ${ }^{25}$ analytic) case-control or cohort studies.

Furthermore, selection bias may also have been a problem because the study sample women were hospital controls and access to hospital care may be more frequent for women of higher socio-economic status than for other women. Women who are more well-off are more likely to live in urban areas and their way of life may more closely resemble that of Western women. On the other hand, women with diseases thought to alter contraceptive practices were not eligible since these were originally controls of a case-control study on steroid contraceptive usage $e^{12-15}$. Also, life habits related to ages of reproductive events (e.g., smoking, diet, drinking) of women hospitalized may differ from the rest of the population. The net bias resulting from these multiple potential sources of selection on international variability remains unpredictable from the secondary analyses performed here because the specific data required to measure it were not collected in the original casecontrol study.

International ecological study correlations may involve a different construct rarely taken into account by individual-level associations ${ }^{11}$. In the present context, our (aggregated) ecological measure, "age at first birth", may represent different etiological aspects relative to breast cancer than the "age at first birth" of an individual woman. Breast cancer is a disease with a complex etiology. Many of its identified or postulated causes, such as timing of reproductive events, body mass or diet, seem to be related to westernization. As a result, an ecological design which uses populations as the units of analysis may be able to assess the full impact of processes affecting populations as a whole rather than subgroups within each population. Indeed, in the WHO Collaborative Study of Neoplasia and Steroid Contraceptives ${ }^{14}$, the risk of breast cancer was found to increase with later age at first birth and later age at menopause, but was not related to age at menarche. Thus, age at first birth was an important risk factor for breast cancer in the individual-level case-control analysis but not an important discriminator of breast cancer incidence across populations. Age at first birth may be modified early in the process of westernization and therefore reaches international homogeneity faster than the breast cancer risk. As a result, we observe similar age at first birth in countries with different age-standardized breast cancer incidence.

This hypothesis is apparently supported by the present results which show a generation effect on the overall association between age at first birth and breast cancer incidence. Although none of the correlations were statistically signi- ficant, the association was weakly positive in the subgroups of study women beyond age 39 years, and weakly negative in the age subgroups $15-29$ and $30-39$ years. (However, as mentioned, all four correlations became (nonsignificantly) positive when People's Republic of China was omitted.) The youngest age subgroup also had the highest median age at first birth. Homogeneity of age at menarche within populations, but variations among populations, would yield no association in case-control studies, but would yield an association in ecological studies. Doubtless, the epidemiological "gold standard" for establishing etiologic associations is an individual-level study (perhaps augmented by measuring and incorporating ecologic variables through a multilevel analysis).

Several elements speak in favor of the validity of the present findings relative to bias. First, the information on reproductive histories obtained in the WHO study was collected uniformly by trained female interviewers using the same questionnaire and methodology. And second, most of the observed correlations were quite strong.

In conclusion, the international ecological correlations observed in this study are in agreement with current beliefs regarding the associations of the reproductive factors age at menarche, age at menopause, duration of reproductive life and, possibly, delay to first birth with breast cancer incidence derived from epidemiological studies based on individual-level data. Thus, it appears that these reproductive factors represent similar constructs when measured on the ecologic and individual levels. The disagreement relative to the association of age first birth with breast cancer incidence observed in individual-level studies versus the lack of association observed in the present ecologic study is not sufficient to question or discount the former finding. Rather, it serves 
to indicate that "age at first birth" represents different constructs depending on whether it is measured on an ecologic or individual level. Resolution of this discrepancy can only be achieved through the development of individual-level study designs which additionally measure and incorporate individual- and supra-individual level variables through multilevel analyses.

\section{Zusammenfassung}

Reproduktive Faktoren und Brustkrebsinzidenz: Eine internationale ökologische Studie

Ökologische Studien helfen, den Zusammenhang zwischen Ereignissen in der reproduktiven Geschichte und dem Brustkrebsrisiko zu verstehen. Wir analysierten die Baten von 9416 Frauen aus den Kontrollgruppen von sieben Ländern (Australien, Volksrepublik China, Kolumbien, ehemalige Deutsche Demokratische Republik, Israel, Philippinen und Thailand) der internationalen multizentrischen WHO-Fall-Kontroll-Studie zu weiblichen Krebsarten. Positive Korrelationen mit länderspezifischen Brustkrebsinzidenzen wurden gefunden für die Dauer der reproduktiven Lebensphase (Median) $(r \geq 0,95 ; p<0,005)$, das Alter bei der Menopause $(r \geq 0,84 ; p<0,025)$ und die Zeitspanne zwischen Erstmenstruation und Erstgeburt $(r \geq 0,59 ; \mathrm{p}<0,22)$ (wenn die VR China nicht mitgerechnet wurde: $r \geq 0.85, \mathrm{p}<0.07)$. Die Beziehung zwischen dem Alter bej der Erstgeburt und der Brustkrebsinzidenz war schwach positiv im gesamten Sample (korrigiert für Alter: $r=0,18 ; \rho=0,73$ ), aber schwach negativ in den Altersgruppen der 15- bis 29-Jährigen und der 30-bis 39-Jährigen und schwach positiv in der Altersgruppe der 40- bis 49Jährigen und der 50 bis 64-Jährigen. Eine starke inverse Korrelation wurde zwischen dem Alter bei der Erstmenstruation und der Brustkrebsinzidenz beobachtet $(r \leq-0,84, p<0,03)$. Diese internationalen ökologischen Korrelationen stimmen mit den Resultaten aus früheren Studien zu Einzelpopulationen überein, wo Beziehungen zwischen höherem Brustkrebsrisiko und jüngerem Alter bei der Erstmenstruation, älterem Alter bei der Menopause, längerer Dauer der reproduktiven Lebensphase und (möglicherweise) grössere Zeitspanne zwischen Erstmenstruation und Erstgeburt gefunden wurden. Im Gegensatz zu Studien, die individuelle Daten analysieren, korrellert das Alter bei der Erstgeburt nur schwach mit der Brustkrebsinzidenz in ökologischen Studien. Dies deutet darauf hin, dass diese Variable unterschiedliche Konstrukte repräsentiert, je nachdem ob sie auf ökologischem oder individuellem Niveau gemessen wid.

\section{References}

1 Ewertz M, Duffy SW, Adami HO, et al. Age at first birth, parity and risk of breast cancer: a meta-analysis of 8 studies from the nordic countries. Int J Cancer 1990; 46: 597-603.
2 Nagata $C, H u Y H$, Shimizu $H$. Effects of menstrual and reproductive factors on the risk of breast cancer: meta-analysis of the casecontrol studies in japan. Jpn J Cancer Res 1995; 86: 910-5.

3 Russo IH, Russo J. Role of hormones in mammary cancer initiation and progression. J Mammary
Gland Biol Neoplasia 1998; 3: 49-61.

4 Pathak DR, Whittemore AS. Combined effects of body size, parity, and menstrual events on breast cancer incidence in seven countries. Am J Epidemiol 1992; 135: 153-68.

5 Kelsey JL, Gammon MD, John EM. Reproductive factors and breast cancer. Epidemiol Rev 1993; 15: 36-47.

6 MacMahon B, Cole P, Lin TM, et al. Age at first birth and breast cancer risk. Bull World Health Organ 1970; 43: 209-21.

7 Pisani P. Breast cancer: geographic variation and risk factors. J Environ Pathol Toxicol Oncol 1992; 11:313-6.

8 Baanders AN, de Waard F. Breast cancer in Europe: the importance of factors operating at an early age. Eur J Cancer Prev 1992; 1: 285-91.

9 Morabia A, Khatchatrian N, Bernstein $M$, Walker DM, Campana A. Reproductive characteristics of a population of urban Swiss women. Acta Obstet Gynecol Scand. 1996; 75: 838-42.

10 Morabia A, Costanza MC. International variability in ages at menarche, first livebirth, and menopause. World Health Organization Collaborative Study of Neoplasia and Steroid Contraceptives [published erratum appears in Am J Epidemiol 1999 Sep 1; 150(5): 546]. Am J Epidemiol 1998; 148: 1195-205.

11 Schwartz S. The fallacy of the ecological fallacy: the potential misuse of a concept and the consequences. Am J Public Health 1994; 84: 819-24.

12 Endometrial cancer and combined oral contraceptives. The WHO collaborative study of neoplasia and steroid contraceptives. Int J Epidemiol 1988; 17: 263-9.

13 Epithelial ovarian cancer and combined oral contraceptives. The WHO collaborative study of neoplasia and steroid contraceptives. Int J Epidemiol 1989; 18: 538-45.

14 Breast cancer and combined oral contraceptives: results from a 


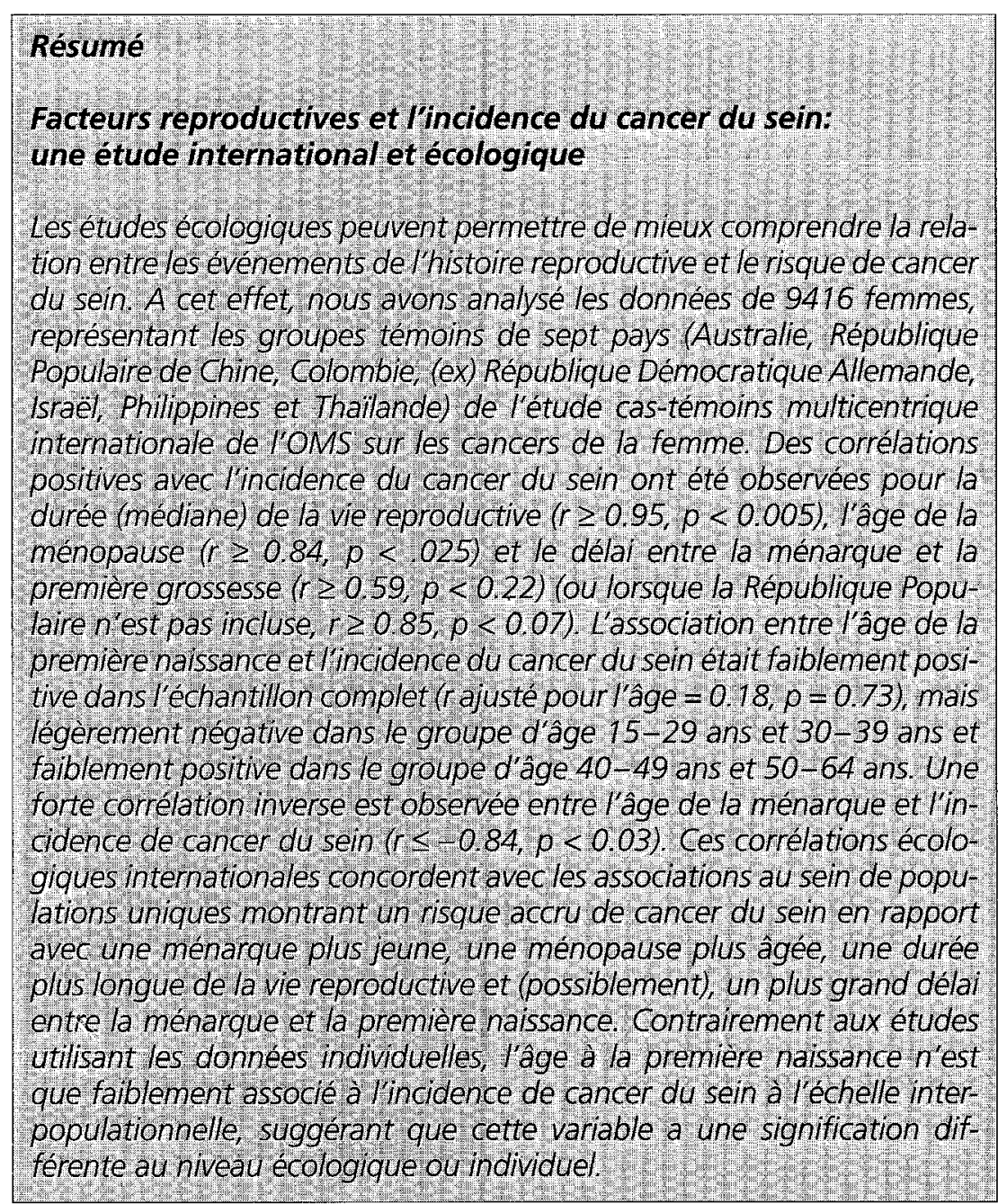

multinational study. The WHO collaborative study of neoplasia and steroid contraceptives. $\mathrm{Br} \mathrm{J}$ Cancer 1990; 61: 110-9.

15 Invasive cervical cancer and combined oral contraceptives. WHO collaborative study of neoplasia and steroid contraceptives. BMJ 1985; 290: 961-5.

16 Cancer incidence in five continents, Volume VI. International Agency for Research on Cancer (WHO). Lyon: IARC; 1992: 956-7, 1014-9.

17 Kalbfleisch $J D$, Prentice $R L$. The analysis of failure time data. New York: J. Wiley and Sons, 1980.

18 Russo J, Tay LK, Russo IH. Differentiation of the mammary gland and susceptibility to carcinogene-

\section{2: 5-73.}

19 Henderson BE, Ross RK, Judd $H L$, Krailo $M D$, Pike $M C$. Do regular ovulatory cycles increase breast cancer risk? Cancer 1985; 56 : 1206-8.

20 Richardson S, Stucker I, Hemon D. Comparison of relative risks obtained in ecological and individual studies: some methodological considerations. Int J Epidemiol 1987; 16: 111-20.

21 Greenland $S$, Morgenstern $H$. Ecological bias, confounding, and effect modification [published erratum appears in Int J Epidemiol 1991; 20: 824] [see comments]. Int J Epidemiol 1989; 18: 269-74.

22 Greenland $S$, Robins $J$. Invited commentary: Ecologic studies biases, misconceptions, and counterexamples. Am J Epidemiol 1994; 139: 747-60.

23 Lagarde F, Pershagen G. Parallel analyses of individual and ecologic data on residential radon, cofactors, and lung cancer in Sweden [see comments]. Am J Epidemiol 1999; 149: 268-74.

24 Sheppard L, Prentice RL, Rossing $M A$. Design considerations for estimation of exposure effects on disease risk, using aggregate data studies. Stat Med 1996; 15: 1849-58.

25 Lasserre V, Guihenneuc-Jouyaux C, Richardson $S$. Biases in ecological studies: utility of including withinarea distribution of confounders. Stat Med 2000; 19: 45-59.

\section{Acknowledgement}

The present study was supported by a grant from the Geneva Anti-Cancer League. The WHO Collaborative Study of Neoplasia and Steroid Contraceptives received primary financial support from the UNDP/UNFPA/ WHO/World Bank Special Programme of Research, Development and $\mathrm{Re}$ search Training in Human Reproduction, World Health Organization; and supplemental support from Contract No. N01-HD-52901 from the US National Institute of Child Health and Human Development.

\section{Address for correspondence}

Alfredo Morabia, MD, PhD

Division of clinical Epidemiology

Geneva University Hospital

CH-1211 Geneva 14

Tel.: ++4122372 9552

Fax: ++41223729565 


\section{Appendix}

The data collection centers, and the principal investigator (PI), co-investigator $(\mathrm{CI})$, and pathologist $(\mathrm{P})$ at each participating center in alphabetical order by country, are as follows:

University of Sydney, Department of Public Health, Sydney, Australia: Geoffrey Berry (PI), Robert MacLennan (CI), Rodney Shearman (CI), Tatiana Jelihovsky (P), Joan Cooper Booth (P).

University of Chile, Faculty of Medicine, Hospital Jose Joaquin Aguirre, Department of Obstetrics and Gynecology, and the Ministry of Health, Hospital Salvador, Department Obstetrics and Gynecology, Santiago, Chile: Ramiro Molina (PI), Luis Martinez (CI), Oriana Salas (CI), Alfredo Dabancens (P).

Shanghai Institute of Planned Parenthood Research, Shanghai, China: Chen Zhiheng (PI), Tao Yun (CI), Hu Yong Wei (P).

Hospital Universitario, WHO Collaborative Center for Research in Human Reproduction, Cali, Colombia: Alvaro Cuadros (PI), Nubia Aristizabal (P).

Central Institute of Cancer Research, Academy of Sciences of the German Democratic Republic, Berlin, Germany: K. Ebeling (P), P. Nishan (C), D. Kunde (P).

Chiam Sheba Medical Center, Department of Clinical Epidemiology, Tel Hashomer, Israel: Baruch Modan (PI), Elaine Ron (CI), Esther Alfandary (CI).

University of Nairobi, Nairobi Center for Research in Reproduction, Nairobi, Kenya: J.G. Mati (PI), Patrick Kenya (CI), Alfred Kungu (P), D. Gatei (P).

Hospital General de Mexico, Mexico City: Hector Rodriguez Cuevas (PI), Socorro Benavides Salazar (CI), Antonio Palet (P), Patricia Ontiveros (P).

University of the Philippines, College of Medicine, Manila, Philippines: Ruben A. Apelo (PI), Julietta R. de la Cruz (CI), Jose Baens (CI), Benita Javier (P).

Chiang Mai University, Faculty of Medicine, Chiang Mai, Thailand: Suporn Silpisornkosol (PI), Tieng Pardthaisong (CI), Nimit Martin (CI), Choti Theetranont (P).

Chulalongkorn University, Faculty of Medicine, Department of Obstetrics and Gynecology, WHO Collaborating Centre for Research in Human Reproduction, Bangkok, Thailand: Banpot Boosiri (PI), Supawat Chutivongse (PI), Pramuan Virutamasen (CI), Chansuda Wongsrichanalai (CI), Prasarn Jimakorn (P).

Mahidol University, Faculty of Medicine, Siriraj Hospital, Department of Obstetrics and Gynaecology, Family Planning Research Unit, Bangkok, Thailand: Suporn Koetsawang (PI) Daungdao Rachawat (CI), Nivat Chantarakul (P).

University of Tromsf, Institute of Medical Biology, Tromsf, Norway: Helge Stalsberg (Reference Pathologist).

Fred Hutchinson Cancer Research Center, Division of Public Health Sciences, Seattle, Washington, United States of America; Coordinating Center: David B. Thomas (Study Coordinator), Elizabeth A. Noonan. (Statistician).

World Health Organisation, Olav Meirik, Timothy M.M. Farley, and Susan Holck, Special Programme of Research, Development and Research Training in Human Reproduction, Geneva, Switzerland. 